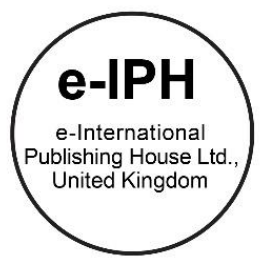

\title{
The Implication of Slum Relocations into Low-cost High-Rises: An Analysis through the infrastructure of everyday life
}

\author{
Faziawati Abdul Aziz*, Norhuzailin Hussain, Norsidah Ujang \\ Department of Landscape Architecture, Universiti Putra Malaysia, Serdang 43400, Malaysia
}

\begin{abstract}
This paper presents the implications of slum relocation into low-cost high-rise housing development. Desa Mentari was selected as a case study for this research where its characteristics as a low-cost high-rise residential for relocated former squatter dwellers best fit the requirement. The data were then analysed against the five domains of the Infrastructure of Everyday Life which are home and neighbourhood, sources of support, making ends meet, enjoyment and having a say. From the analysis, the author established that the major implications are the breakdown of the community structure, the rise of social ills, the deficient living environment and racial conflicts. The work conclusively argues that housing and planning policies should put much consideration into the everyday life activities, issues and needs of particular communities within society.
\end{abstract}

(C) 2016. The Authors. Published for AMER ABRA by e-International Publishing House, Ltd., UK. Peer-review under responsibility of AMER (Association of Malaysian Environment-Behaviour Researchers), ABRA (Association of Behavioural Researchers on Asians) and cE-Bs (Centre for Environment-Behaviour Studies), Faculty of Architecture, Planning \& Surveying, Universiti Teknologi MARA, Malaysia.

Keywords: Infrastructure of everyday life; slum relocation; community breakdown; low-cost housing

\section{No Lesson Learned}

Kuala Lumpur underwent rapid urbanisation and industrialisation in the 1980s and 90s, which saw major demolitions of squatter settlements in replace for new mega development projects. Consequently, this resulted in former squatter dwellers being relocated into low-cost high-rise flats. The tragic death in 1997 of a technical assistant killed by a brick thrown off Flat 92 in Bangsar called for an awareness campaign to educate flat-dwellers on appropriate means of disposing of garbage (Bunnell, 2002). Despite all this, the following years saw other similar non-fatal cases in Penang and Petaling Jaya occurring. These incidents further highlight the dwellers' inability to adapt to this type of housing. Nevertheless, the rationale behind relocating former squatters' dwellers into high-rise apartments remained unchallenged as more relocation programmes were carried out. No lesson was learned from the incident, in fact, it was blamed on the mal-adaptation of former squatter dwellers to living in flats, and their 'kampung' mentality and values that they brought with them (ibid). Kampung is a Malay word that means villages, and it

${ }^{*}$ Corresponding author. Tel.: +603 89464057; fax: +603 89480017

E-mail address: faziawati@upm.edu.my

(C) 2016. The Authors. Published for AMER ABRA by e-International Publishing House, Ltd., UK. Peer-review under responsibility of AMER (Association of Malaysian Environment-Behaviour Researchers), ABRA (Association of Behavioural Researchers on Asians) and cE-Bs (Centre for EnvironmentBehaviour Studies), Faculty of Architecture, Planning \& Surveying, Universiti Teknologi MARA, Malaysia.

DOI: https://doi.org/10.21834/e-bpj.v1i2.253 
is commonly used to describe something that is out-dated or non-modern (Maliki et al., 2015). Therefore, these values are deemed as unacceptable for urban living and perceived as primitive.

Though there is some truth to the above allegation mainly regarding their conduct on garbage disposal, the developers and local authorities are partially responsible. The housing development was developed only to the minimum requirements and was described as 'pigeon holes' and 'chicken coops' due to the size and structure of the buildings (Bunnell, 2002; Yeoh, 2001). Syed Husin (1998) also highlighted the issue of inadequate living conditions, poor workmanship and the lack of facilities and amenities. Problematizing certain community groups for the benefit of others does not sit well with the author as everyone regardless of their racial and financial background should have access to better homes. The demolishment of perkampungan setinggan (squatter settlements) was mostly under the impression that they were breeding grounds for crimes and social ills, and its uninhabitable living environments. Therefore, the relocation into low-cost high-rise was considered as an effort to improve the living quality of these former squatter dwellers. However, different community has various issues thus developing one relocation programme for all does not solve their problem. The primary concern for Desa Mentari was the racial tension between the Malays and the Indians (Abdul Aziz, 2012) hence this development does not suit their community, as well as not providing them with the quality of life that they previously lived.

\section{Low-Cost High-Rise as a Method of Solution}

In 2001, the state of Selangor introduced the 2005 Zero Squatter programme and later launched a major series of relocation project. The year 2004 saw most of the evictees successfully relocated into their new homes that were conducted in phases. The project that was named Program Perumahan Rakyat (PPR) Bersepadu (Integrated People Housing Programme) was commissioned to relocate former squatter dwellers from the main cities in Selangor and was also implemented in other states throughout Malaysia such as Pulau Pinang, Perak, Sabah and Sarawak. The programme consisted of one- and two-storey lowcost terrace houses, 11- to 12-storey and 16- to 22-storey low-cost high-rise flats (Sufian \& Mohamad, 2009). The evictees were given the right to choose between the two types of housing. Logically, the more comfortable terrace houses would be the preferred choice; however, this was not the case. With this kind of development located at the outskirt of town, the high-rise flats become the best option for the majority of former squatter dwellers as it is situated in major towns nearer to where they work. Despite consisting of three bedrooms, these flats are relatively small as compared to their former homes. Comprising an average of five to six or more members per household (Mat Zin, 2005), it was a little too cramped for some of the residents. On top of that, the facilities and amenities are inadequate, and the workmanship of the flats is below standard. Only two elevators were provided for the 17- to 22-storey residential which are insufficient for the densely populated blocks, and no garbage disposal system (chute) was installed (Bunnell, 2002; Syed Husin, 1998; Sufian \& Mohamad, 2009; and Jayasooria, 2008). A house should not just provide shelter from the physical elements, it should also provide social, spiritual and psychological stability to its dwellers (Abdul Karim \& Hashim, 2010). In the case of Desa Mentari, the lack of facilities and amenities brought to the lack of healthy physical activities that led to social ills in these areas. The environment is unhealthy, and studies have shown that this has an effect on the children's performance in school (Sufian \& Mohamad, 2009). The government and local authorities failed to acknowledge the multi-racial and multi-religion composition as well as the various cultures that make up this community. Their insensitivity in designing the development and the insufficient provision of spaces for religious practices and cultural festivities impacted the community's integration hugely as racial conflicts escalated in these areas. Jayasooria (2008) stated that the Government's often insensitive provision of facilities and designs in developments with multicultural and multi-religious communities has had an adverse impact on community integration. Eventually, what was supposedly a more appropriate modern residential for the former squatter dwellers, in turn evolved into a vertical slum. To make matter worst, it now is the breeding ground for crime and social ills.

\section{Methodology}

This research employed the case study strategy and undertook primary data collection through interviews. The interviews were a combination of mainly semi-structured and structured formats, using focused and open-ended questions in guiding respondents to their expert or personal knowledge but at the same time allowing them to enunciate their opinions. The process took place over a six-month period, ranging from focus groups to formal one-on-one interviews. Desa Mentari has been chosen 
as the most fitting case study for this research due to its characteristic that is a residential development for relocated squatter dwellers. Its community was the primary unit of analysis with the professionals being the sub-unit of analysis. Questions were asked regarding crime and safety, community and racial issues, the physical attributes, their living condition, the management of the compound, the authorities' and other agencies' contributions, and what can improve their neighbourhood and the quality of their lives. The questions designed for the professionals and non-governmental agencies were more in-depth acquiring expert opinions on the background and history of the community, relocations processes and housing policies, as well as the underlying issues faced by the community.

An environmental observation was also conducted, as it is imperative that a researcher has a clear understanding of the context or the phenomenon being studied, and a first-hand experience of the site as part of the fieldwork as case study takes place in the natural setting of the 'case' (Yin, 2009). Observations were made during numerous field visits at different periods of times and days of how the spaces were used, for instance, and to have a clearer view of the building conditions, living environments, facilities and amenities, and other elements that indicated impoverishment as reported, as well as the local identity and culture of the community. Photographs of the site were taken as valuable proof to support the findings. To strengthen the key points of the study, the author also employed a group of teenagers who participated in the focus group to also take part in the observation by taking photographs of what they did not like about their neighbourhood. These two sets of photographs were then compared and analysed.

Overall, a total of 22 one-to-one interviews were conducted, of which 13 were with the professionals and nine with the residents. The first gatekeeper from the Social Strategic Foundation assisted the author with the first five Indian family respondents while the remaining four were either approached by the author or introduced by the second gatekeeper ${ }^{\dagger}$. Meanwhile, the professionals were selected based on their area of expertise that applies to the research. The focus groups were conducted during the second leg of the data collection process. Two focus groups were organized with the Malays and the teenagers comprising of eight to 12 respondents per group $\ddagger$.

\subsection{The case study}

Desa Mentari consisted of ten residential flats, two of which are located in Taman Medan, PJS 2, and eight blocks in Taman Desaria, PJS 5. The development was developed in four phases over the years 2004 to 2006, the 17-storey blocks in Taman Medan being the last stage. These blocks are located directly along the New Pantai Expressway (NEP), surrounded by low-cost terrace houses and apartments, abandoned developments as well as new commercial buildings. The author focused on Desa Mentari in Taman Medan, PJS 2 as a sample for this research. The two residential blocks consisted of 697 housing units per block with an average of five to seven residents per household (Ismail, 2005). Each housing unit is 60 square feet per unit, consisting of three bedrooms, two bathrooms, one living and dining area and a kitchen. The Malays and the Indians make up the majority of the community, followed by a small number of Chinese and foreigners, mainly Indonesians and Bangladeshis.

\footnotetext{
${ }^{\dagger}$ For the Indian community, most of them were interviewed as a family accompanied by a gatekeeper. They were contacted by the Social Strategic Foundation beforehand, and had volunteered to be interviewed.

‡ Focus groups were only conducted with the Malays, as they were more comfortable being interviewed in groups rather than individually.
} 


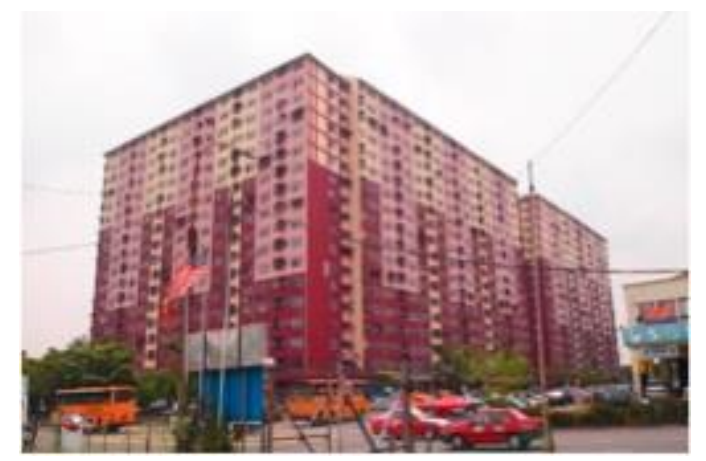

Fig. 1. The 17-storey Desa Mentari high-rise residential blocks (Picture taken by author)

\subsection{The application of the infrastructure of everyday life}

Both the professional and community data was analysed against the five domains of the Infrastructure of Everyday Life. The five domains are home and neighbourhood, making ends meet, enjoyment, sources of support and having a say. Developed by Horelli, Booth and Gilroy, the approach began as a concept that focuses on how women conduct their everyday routines, and is committed "to create material and socio-cultural support structures - the infrastructure of everyday life" (Gilroy \& Booth, 1999). It concentrates on the spatial compositions by which child care options and working hours, for example, are determined by the structuring and arrangement of housing, services and jobs within a residential development. The approach disapproves the traditional methods of urban planning and policies, the lack of centralised solutions in resolving the issues of everyday life, the depreciation of unpaid work such as caring for the community, and the gaps in voices heard and participations (Horelli et al., 1998). Previously, work, care and housing were separated, when, in fact, it should be integrated within the neighbourhoods. Namely, the approach is concerned with attempting to merge the management of space and time of the dwellers' everyday routine with relaxing, caring and working feasibly. For this to materialised in planning and policy development, it is crucial first to understand the day-to-day life of said community and find means to respond to the people's needs.

According to Gilroy and Booth (1999), there are five domains of the Infrastructure of Everyday Life that apply to all regardless of income, age and gender that are:

- home and neighbourhood - neighbourhood and its surrounding environment, the living conditions, facilities and services;

- making ends meet - employment, affordable goods and services;

- enjoyment - religion and culture, infrastructure for socializing and relaxing;

- sources of support - friends and family, community network, spiritual support; and

- Having a say - participate in decision-making regarding the community, the right to be heard.

Nevertheless, it is important to understand that home and neighbourhood is the primary domain as it accommodates and caters to the other four areas. The household is the central element, each with its distinctive characteristics such as age group, socioeconomic factors, race and gender. According to Speak (2012), the relationship among the five domains and household's characteristics can be clearly understood and interpreted through the framework. Each element within the domains is complementary to each other, establishing balance in creating a better living based on daily routines and experiences. Gilroy (2008) further developed the framework where she observed that four of the five domains are in fact ingrained within the home and neighbourhood domain (refer figure 2). She stated that our neighbourhood and its environment already accommodate the majority of the resources that are central to the other four domains. 
Abdul Aziz, F., et al. / 2nd AQoL2015lzmir, Turkey, 09-14 Dec. 2015 / E-BPJ, 1(2) July 2016 (Pp. 33-42)

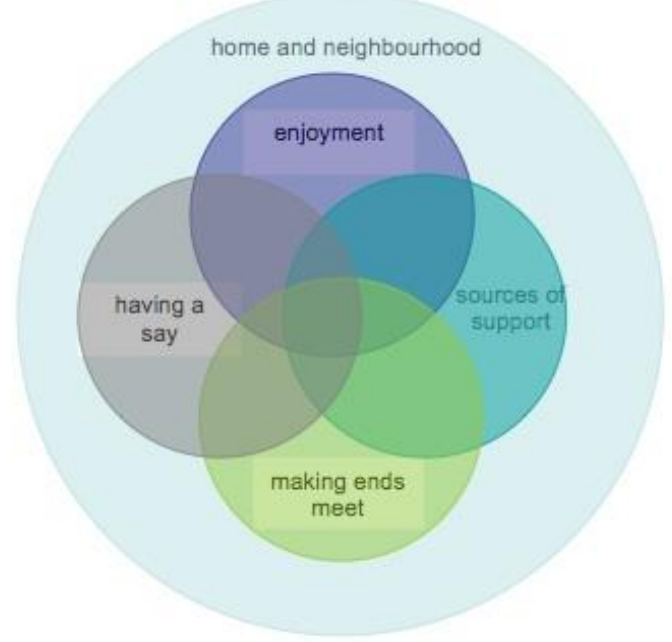

Fig. 2. The four domains ingrained within the home and neighbourhood domain (Speak, 2012) 


\section{Findings}

The analysis of the data collected produced a description of Desa Mentari's social, cultural and physical characteristics. For this paper, three main issues will be discussed which are as follow:

\subsection{Breakdown of community structure}

The majority of the household respondents stated that their community is no longer united since the relocation. Despite the fact that the flats are overpopulated, some of the dwellers still do not know their neighbours. In fact, dwellers that were previously from the same squatter settlements no longer socialise with each other. They claimed that the community is more self-centered, low on civic consciousness, and ignorant when it comes to their surroundings and fellow neighbours. Meanwhile, one of the professional respondents explained that this is due to the fact they are not a settled community as yet and is still rebuilding the community's integration. Others maintained that the community has no sense of belonging or attachment to their new home. The respondents keep reminiscing their life back at their former squatter settlement, which the local authority accused of wanting to live for free. In reality, it was the kampung lifestyle that they missed and preferred.

The community structure (sources of support) was fragmented by the relocation that resulted in the lack of cooperation in communal activities and neighbourhood watch, and lack of community spirit and engagement. This fragmentation leads to other issues such as disputes among community members, cleanliness, crimes and social ills. Nadarajah (2007(b)) best describes the breakdown:

"For many, the neighbourhood was and is their community, a place that is familiar and supportive at times of great difficulties. In moving across to new complexes such as Desa Mentari, where a sense of neighborhood has to be re-established, there is for a period of time, a sense of loss of "community". Such mobility presents the challenges of making new friends and sharing scant resources, especially in such a dense collective living environment. As one resident commented, "I feel alone now. I feel I have been left on my own - not even my children look after me. I feel abandoned. In the kampung, it was different then - we knew each other and had to rely on each other. I could talk to people, and they would say hello".

\subsection{Racial conflicts}

As previously mentioned, the Desa Mentari community consisted mainly of two major ethnic groups, which are the Malays and the Indian, both formerly lived in homogenous neighbourhoods. Despite now living in a multiracial residential, they still function as two independent communities. Conflicts are common as both groups failed to accommodate themselves to their new multi-religious and multicultural environment. Both communities were not prepared beforehand on how to adapt, understand and tolerate other religion and culture. Adjusting to the new, unfamiliar environment is hard work for them, thus resulted in a disjointed community and lacking in sources of support. Furthermore, the design of the flats itself does not take into account the cultural and religious aspects (enjoyment) of the community. No religious spaces for prayers such as surau (small mosque) and small temples are provided in the development, which led the Malays converting one of the shop lots into a surau, and the Indians with nothing as they need free standing structure. This lack of facilities further compounded to the disunity, as one group is given priority to openly practise religious beliefs (enjoyment) and to dictate spaces for that purpose, which inevitably creates conflicts. On top of that, communal activities and festivities are conducted on the ground floor shop lots that were opened up and used as a 'hall'. As this 'hall' was originally designed as shop lots, it does not function well and is insufficient to fit and support thousands of residents. To add more to the friction, not everyone has access to the hall as the Malays have full control regarding what functions can be held there.

This is not to say that the community is racists or incapable of living with other racial groups. The central issue behind the conflicts is due to poverty (making ends meet), as stated by Associate Professor Dr. Mansor Mohd. Noor in a research he conducted regarding the infamous Kampung Medan incident: "If you are poor, you have the same problems. This is our problem, not a Malay or Indian problem" (Damis, 2007). He then added that socio-economic issues materialise in the form of racial (terms):

"Even though the conflict seemed to be racially-based, issues of urban poverty, marginalisation and social neglect were the factors that caused the conflict" (ibid). 
The statement above is also supported by Nadarajah (2007(a)) who claimed that frustration and outrage primarily triggered the racial clash in 2001 due to the living environment (home and neighbourhood) and marginalisation rather than by racial issues. Hence, to resolve any racial issues in Desa Mentari, it is important first to address the root problem of this community that is poverty, through education (sources of support) and strong economic policies (making ends meet).

Despite all this, the community still maintains some positive kampung value such as getting together for wedding preparation. However, due to no provision of communal spaces within the development, the community resorted to using corridors to conduct such activities. Consisting of two religious groups, the Muslims and the Hindus, this could have made for a vibrant community. Unfortunately, the development does not honour and reflect the religious and cultural diversity that exists. Religion is a very sensitive matter, and this comes with restrictions. There was a case where an Indian family was not allowed to hold a funeral at the hall because it was usually used for Malay weddings. As it was impossible for them to bring up the deceased to the family's home, the funeral eventually was held in the parking lot. The family were robbed of their rights to mourn privately. This is an issue that has been grumbled upon continually. However, no action has yet been taken by the local authority. These issues highlight how greater community participation (having a say) is necessary during the relocation process in preventing frictions especially in areas known to have racial conflicts. However, any such programme was not organised during that time.

\subsection{Physical attributes}

The physical condition of Desa Mentari is a major concern for both the professional and household respondents. As stated earlier, the sizes of each unit are unaccommodating to the almost 7000 squatter families that were crammed into the ten residential blocks. The flats are over-crowded, there is no privacy between neighbours and the common spaces on each level are compact. Spaces for recreational (enjoyment) lacks apart from the uninspiring playgrounds and a basketball court in Taman Desaria, PJS5. Safety issues are not addressed, and necessary facilities (that are essential for home and neighbourhood) are deficient. Cleanliness is another major concern for the community where the squalid, unhealthy environment has had an adverse impact on their everyday life. Additionally, the quality of the flats in itself does not meet the standards and the environment as a whole does not promote for a healthy living. Even worse, a research done on children who were relocated to low-cost flats and living in an unhealthy environment were found to perform poorly in school (Siti, 2006; as quoted in Suffian and Mohamad, 2009), which is the case for most children in Desa Mentari.

The physical attribute of the residential is the central element of the home and neighbourhood domain. Therefore, it is an integral factor that determines the development of a harmonious community. Regarding Desa Mentari, its development only meets the minimum or less of the building guidelines. Thus, the bad design and use of materials, as well as insufficient facilities and amenities, lead to frustrations. The flats are poorly constructed using cheap materials and are not safe to be inhabited, as reported in The Malay Mail (2009), which then contributes and adds ups to most of the issues faced by the community. The poor development is in total contrast to what was envisioned by the Zero Squatter programme and the housing policy that states all citizens are entitled to quality houses complete with sufficient facilities and services. The community should have been given the right (having a say) to determine their needs in the development of the settlement, or at least were allowed to participate or included in the design process. It is always the case where the designers and policy makers believing that they know what is best for the community because they are the professionals and experts when in reality the community are the ones that know what is best for them.

\section{Discussion and Recommendations}

In the context of the Infrastructure of Everyday Life, the everyday tasks of a community are at the centre of the concept as the aim is to reorganise "the basic tasks of daily life in neighbourhoods in a more integrated ways" (Horelli et al., 1998). This means that the component of the framework is already embedded in the community, and it is a matter of identifying common everyday activities of the community and using those as a basis for the development of policies. The following are some recommendations based on the five elements of the Infrastructure of Everyday Life: 


\subsection{Home and neighbourhood}

The deterioration and aging of buildings is a natural process that occurs over time and eventually these buildings would turn into slums. For Desa Mentari, it happened quickly within the five years after the community was relocated. The causes of the transformation in such a short period are threefold. Firstly, the buildings were built using cheap materials, and the safety of the buildings' structure is questionable as they were only awarded temporary Certificates of Fitness (CF) (The Malay Mail, 2009). Secondly, the development only conformed to the minimum requirements of the building guidelines and does not take into consideration the nature of the people that were to relocate there. Finally, the deterioration was partly due to the attitude of the residents itself which proves that placing people into better accommodations does not simply change and mould behaviours and attitudes. This study has established that the sense of belonging within the community is low which contributed to them not treating the flats as a home for which they care.

It is anticipated and proven that if measures are not taken to improve the way these settlements are designed, developed and managed, the cycle of slums resurfacing will continue. A comprehensive research regarding the community and its issues must be conducted before any development. As previously discussed, the design should adapt to the nature of the Desa Mentari's community especially concerning racial integrations, three generation household, diverse age groups, economic status and the kampong-style community lifestyle. The issue of housing units being too small to fit big households can be resolved by providing multi-size units per building. Instead of having the standard three-bedroom for all, developers should provide a range of twobedroom to four-bedroom units to suit different households and also incomes.

\subsection{Sources of support}

Another issue that keeps resurfacing is the breakdown of the community structure. The community is yet to grasp the idea of a multi-racial community and, as the new settlement has no clear identity that they can relate to, it takes time for the integration to develop. Coming from homogenous communities, adapting is a challenge for them, coupled that with a history of racial clashes between them, the situation worsens since they were relocated. The social control system, both informal and formal, was strong in the perkampungan setinggans with local leaders and community associations, and the residents were more involved in their community. Moving into Desa Mentari, they no longer have familiar neighbours and friends on whom to fall back on in times of need.

There is a need for the local authority to organise activities and provide spaces that cater to and are sensitive to the various rituals of different religions and cultures. These activities should, at the same time, celebrate this diversity as well as promote healthy community interactions. The local authority must be fair in the provision of facilities and services that should be inclusive of all the members of the community. It should provide one shared multi-functional space, such as the void deck in Singapore's public housing, to be used by the whole community for them to socialise, open bazaars and food stalls, and conduct festivities and weddings and any other communal activities. For more sensitive, private events such as funerals, reserved space for these purposes should be provided. Programmes that foster multi-religious understanding and tolerance should also be organised. Strong leadership is also essential in uniting the two communities; therefore someone outside the community whom they can trust and rely on should be appointed.

\subsection{Having a say}

The participation of the community is a vital component in ensuring the success of the framework, or any other framework for that matter. There is a need for change in the political priorities of the central government and a change in approach from centralisation to decentralisation, market driven to pro-poor and people centred, and restriction to enabling. An essential change in policy is to give the voice back to the people or simply known as public participation. This does not mean that the community has full power over all decisions regarding their neighbourhood, but developing collaboration and a professional relationship between communities and the local authorities by decentralising power in the decision-making process enables the community to assist in the planning or improvement process. Only the community knows its financial situation, the social aspects of their community, the issues faced and the needs of the residents to conduct their daily lives. Therefore, they should be involved in discussions, especially in identifying the problems and their strengths. This is to ensure and determine that "the quality of life in a 
community should reflect the wishes of those who live there rather than represent purely technical solutions imposed from outside" (Baycan-Levent and Nijkamp, 2009). They should also be involved in the management and maintenance of their neighbourhood, unlike now where the buildings are wholly managed by the developer. By allowing the community to have some control in the management of their settlement, a sense of belonging to the place would eventually be promoted, which is something that is currently lacking.

\subsection{Enjoyment}

Enjoyment is essential for the community to lead a quality, healthy and spiritual lives. In the case of Desa Mentari, another common issue that was raised is the lack of facilities provided for the community to conduct religious, recreational and communal activities. Those that were provided are insufficient, compromised and simply provided just to meet the minimum planning requirements. These facilities are built using leftover spaces or the community itself created spaces for use with their efforts. There are no acceptable reasons that can explain why the developer and the local authority failed to provide necessary facilities such as communal halls and open spaces other than playgrounds for the community. Without these facilities, a community cannot function well and will always feel neglected. This situation, inevitably builds feelings of hatred and mistrust towards the local authority and the Government in general, thus further weakening the bond between the poor and the authorities. The bad design of the settlement clearly demonstrates the laid-back 'I do not care' attitude of the developers who designed and developed the settlements and the local authority that approved the development.

\subsection{Making ends meet}

Although the community was living for free back in the perkampungan setinggan, they were leading a hard life, scarcely living off limited resources as the majority of the dwellers belong to the lowest income group in Malaysia. In moving to Desa Mentari, although their physical environment improved, life is more difficult as they now need to pay for mortgages and bills. On top of that, they face extreme hardship due to the increasing cost of living in the city. This puts pressure on families as both parents have to work long hours, and that affects the quality of family life, which leads to other issues in the community. Desa Mentari should not only function as the home of the dwellers, but it should also be a place where they can generate income, which is common among low-income communities. Therefore, the design of the buildings must allow income generation activities to be conducted by providing proper spaces, as previously mentioned. Home-based Enterprises (HBEs) are known to have a significant effect on household incomes and the improvement of the livelihoods of the community, especially as they do not require many skills in which most of the community is lacking. However, for those who are interested in learning new skills, training programmes specifically for HBEs should be developed. The Government agencies need to provide a wider range of services to address the complex nature of this community. There is a need for assistance in the area of income generation through cross-sectional services, not just the help of one agency. Most importantly, these services must reach the target group, and these agencies and services must be made accessible to the community, not just through the media or the web, of which some of the residents have no knowledge and to which they have no access.

\section{Conclusion}

This paper has highlighted three main issues that arise due to the relocation and discussed them against the five elements of the Infrastructure Everyday Life which are home and neighbourhood, sources of support, enjoyment, making ends meet and having a say. Home and neighbourhood relates to the living condition as a whole including services and facilities. In the case of Desa Mentari, necessary facilities and amenities are insufficient or non-existing, and the cleanliness and maintenance of the building blocks are a major issue. When the physical attributes are not taken care of, it negatively impacts the everyday lives of the community. Sources of support include both informal and formal supports, be they in the form of transportation, policing, neighbourhood watch, health facilities or even supports from family and friends. As discussed above, this research found that the main issue concerning the social aspect of the neighbourhood is the breakdown of the community's structure. The decline hugely affected their integration, and the situation can be best described as inharmonious. The kampung spirit that once was significant, as well as its identity as a perkampungan setinggan, has evaporated. 
As for enjoyment, it is not just about fun and games, it also includes spiritual and religious activities. This can be achieved through the provision of spaces and facilities that allow dwellers to practise openly their beliefs and hold religious and cultural festivities. The cultural and religious diversity were not taken into account during the design and development processes. Due to the lack of communal spaces, it adds on to the frictions between the two major racial groups as both are fighting over spaces for weddings, festivities and religious purposes. When it comes to having a say, it could be concluded that the community had no say when it comes to the relocation and the development of their new settlement. Again, all development, not just for the poor and relocated, must include the community during the early stage of the development as only the community knows what their problems and needs are. From there, the authorities and developers can come up with the best solution and design for that particular community. Finally, making ends meet looks into how the community sustains itself and whether affordable goods and services and other supporting aids are provided in the neighbourhood. The community were made poorer after the relocation as they now have to pay for their new home; therefore; programmes that help the community to improve their lives financially should be developed as well as training skills classes.

To sum up, this paper would like to stress the need for the implementation of the bottom-up approach to governance, primarily the participation of the households that puts the people and their needs at the heart of policy development. It is suggested that any intervention to be implemented must first seek and understand the reality and the nature of a community, that is, what their real needs and priorities are. The insufficient provision of facilities and services should have never been an issue as these are basic amenities that are required in all developments, and the provision of them should not have been compromised regardless of the status of its residents. Local authorities should be more stringent in the approval of any design of developments, in particular for the lower income groups. Most importantly, the root of the issues faced by the community must first be resolved for any development or improvement to be successful. As proven in the Desa Mentari experience, physical improvement does not contribute to the betterment of the livelihoods of the residents.

\section{References}

Abdul Aziz, F. (2012). The investigation of the implication of squatter relocations in high-risk neighbourhoods in Malaysia. A PhD Thesis submitted to Newcastle University, United Kingdom.

Abdul Karim, H., \& Hashim, A. H. (2010). The effect of a resettlement scheme on the social-cultural changes of the Temuan community. Procedia - Social and Behavioral Sciences, 42, 362-373.

Baycan-Levent, T., \& Nijkamp, P. (2009). 7 FAQs in urban planning. Serie Research Memoranda 0030, VU University Amsterdam, Faculty of Economics, Business Administration and Econometrics.

Bunnell, T. (2002). Kampung rules: Landscape and the contested government of urban(e) Malayness. Urban Studies, 39(9), 1685-1701.

Damis, A. (2007, May 14). Spotlight: Poverty led to Kg Medan Clashes. New Straits Times. Retrieved from http://www.nst.com.my/Current_News/NST/Monday/ National/20070514081411/index_html.

Gilroy, R. (2008). Places that support human flourishing: Lessons from later life. Planning Theory and Practice, 9(2), 145-163.

Gilroy, R., \& Booth, C. (1999). Building an infrastructure for everyday lives. European Planning Studies, 7(3), 307-324.

Horelli, L.; Booth, C., \& Gilroy, R. (1998). The Eurofem toolkit for mobilizing women into local and regional development. Gender and Human Settlements International Conference, 10-12 June.

Ismail, M. (2005). Setinggan dan pemasalahannya serta penyelesaian ke arah setinggan sifar. A Master's Thesis submitted to Universiti Teknologi Malaysia.

Jayasooria, D. (2008). Social development and Indians in Malaysia: An agenda for social inclusion. Malaysia, Yayasan Strategik Sosial.

Maliki, N. Z., Abdullah, A., \& Bahauddin, A. (2015). Recalling the transitional space: City home and kampung home. Procedia - Social and Behavioral Sciences, $170,605-612$. 
Mat Zin, R. H. (2005). Revisiting urban poverty and the issue of social protection in Malaysia. Paper presented at Conference on Urban Poverty and Social Safety Net in East Asia, Beijing, June.

Nadarajah, Y. (2007)(a). Life under the freeway in Malaysia: Community resilience amidst modernization in contemporary Malaysia. Local Global, 4(2007), 70-81. Nadarajah, Y. (2007)(b). The outsider within - commencing fieldwork in the Kuala Lumpur/Petaling Jaya Corridor, Malaysia. International Journal of Asia-Pacific Studies, 3(2), 109-132.

Speak, S. (2012). Planning for the needs of urban poor in the Global South: The value of a feminist approach. Planning Theory, 0(0), 1-18.

Sufian, A., \& Mohamad, N. A. (2009). Squatters and affordable houses in urban areas: Law and policy in Malaysia. Theoretical and Empirical Researches in Urban Management, 4(13), 108-124.

Syed Husin, A. (1998). Squatters and forced evictions in Malaysia. Karachi: City Press.

The Malay Mail Online (2009, July 22). Desa Mentari's distress call. Retrieved from http://www.mmail.com.my/content/8738-desa-mentaris-distress-call.

Yeoh, S. G. (2001). Creolized Utopias: Squatter Colonies and the Post-Colonial City in Malaysia. SOJOURN, 16(1), 102-124.

Yin, R. K. (2009). Case study research : Design and methods. Los Angeles, Calif: Sage Publications. 